\title{
A NOVEL STABILITY INDICATING REVERSE PHASE HIGH PERFORMANCE LIQUID CHROMATOGRAPHY METHOD DEVELOPMENT AND VALIDATION FOR THE QUANTIFICATION OF ARIPIPRAZOLE IN PURE AND ITS PHARMACEUTICAL FORMULATION
}

\author{
VIJAYABHARATHI K, SHAIK MUNEER*, CHANDRA SEKHAR KB \\ Department of Pharmaceutical Sciences, JNTUA Oil Technological and Pharmaceutical Research Institute, Ananthapuramu, \\ Andhra Pradesh, India. Email: muneer.pharma@gmail.com
}

Received: 01 February 2017, Revised and Accepted: 03 March 2017

\section{ABSTRACT}

Objective: This study was aimed to develop a novel, selective, and sensitive reverse phase high performance liquid chromatography method for the detection and quantification of aripiprazole in pure form as well as in its pharmaceutical formulation.

Methods: The chromatography was carried out on C18 Phenomenex Luna $(250 \times 4.6 \mathrm{~mm} \times 5 \mu \mathrm{m})$ column using a mobile phase of $0.1 \% \mathrm{v} / \mathrm{v}$ orthophosphoric acid ( $\mathrm{pH} 3.0)$, acetonitrile and methanol in the ratio of 40:50:10 (\% v/v). The isocratic elution program was adjusted to $1.0 \mathrm{ml} / \mathrm{minutes}$ flow rate with $20 \mu \mathrm{l}$ injection volume. The eluted components were monitored at $254 \mathrm{~nm}$. The ambient column oven temperature was maintained.

Results: The developed method was validated statistically with respect to linearity, range, precision, accuracy, specificity, robustness, ruggedness, detection and quantification limits and also subjected to various stress conditions such as acidic and alkaline hydrolysis, oxidation, photolysis, and thermal degradation. The method showed linearity across the concentration range of $10.0-60 \mu \mathrm{g} / \mathrm{ml}$.

Conclusion: The developed method is specific, precise, accurate, robust and stability indicating which can be successfully applied for routine analysis, quality control analysis and also suitable for stability analysis of assay of aripiprazole in pure form and its formulation as per the regulatory requirements.

Keywords: Aripiprazole, Reverse phase high performance liquid chromatography, Stress condition.

(c) 2017 The Authors. Published by Innovare Academic Sciences Pvt Ltd. This is an open access article under the CC BY license (http://creativecommons. org/licenses/by/4. 0/) DOI: http://dx.doi.org/10.22159/ajpcr.2017.v10i5.17428

\section{INTRODUCTION}

Aripiprazole (APP) is antipsychotic, selective dopamine D2-receptor antagonist with dopamine autoreceptor agoinst activity belongs to the class benzisoxazole derivatives [1,2]. It is chemically Sec2(IH)Quinoline,7-[-4-[4-(2,3-dichloro-phenyl)-1- piperazinyl]butoxy]-3,4dihydro. The chemical structure of APP was shown in Fig. 1. A few method have been reported as single analyte or in combination with other drugs in spectrophotometric studies [3-7] and biological samples include liquid chromatography (LC) [8-12], gas chromatography-mass spectrometry (MS) [13], LC-MS/MS [14-18], capillary electrophoresis [19,20], and LC-ultraviolet (UV) [16] methods. This study was aimed to develop a simple, accurate, precise and robust validated stability indicating costeffective method using reverse phase high performance LC (HPLC) and was extended for its formulations and bulk samples than existing one.

\section{METHODS}

APP working standard was a gift sample from Sun Pharma Laboratories (Chennai). HPLC grade acetonitrile, methanol and AR grade of hydrochloric acid and hydrogen peroxide were purchased from SD Fine Chem. Ltd., Mumbai. HPLC grade water and AR grade orthophosphoric acid was purchased from Merck, Mumbai and sodium hydroxide from Molychem, Mumbai. The pharmaceutical formulation used for the study was ABphyline ${ }^{\circledR} 100$ mg Capsules (Sun Pharma Laboratories, Chennai).

A Shimadzu (Kyoto, Japan) ultra fast LC (LC-20AD) chromatographic system, the output signal was monitored and processed using LC solutions as chemstation, an UV-visible PDA detector (SPD-20AT) and an LC-20AD solvent delivery module was used during the method development and validation. A Phenomenex Luna C18 $250 \times 4.6 \mathrm{~mm}, 5 \mu \mathrm{m}$, column was used as stationary phase. The mobile phase consisted of $0.1 \%$ orthophosphoric acid (pH adjusted to 3.0 with $0.1 \mathrm{M} \mathrm{HCl}$ ), acetonitrile and methanol in a ratio of 40:50:10\% v/v. Before proceeding for analysis, the mobile phase was degassed by use of a Sonicator (Spincotech Pvt. Ltd.) and filtered through a $0.45 \mu \mathrm{m}$ HPLC filtration assembly. Isocratic elution was used with a flow rate of $1.0 \mathrm{ml} /$ minutes. An injection volume of $20 \mu \mathrm{l}$ was used for the analysis and validation of APP. The detection was carried at $254 \mathrm{~nm}$.

Working standard solution was prepared by weighing $25 \mathrm{mg}$ of drug in $25 \mathrm{ml}$ volumetric flask and sufficient amount of methanol was added to dissolve it, and final volume was made up to $25 \mathrm{ml}$ (Stock A; $1000 \mu \mathrm{g} / \mathrm{ml}$ ). Various aliquots from stock A were prepared to obtain concentrations between 10 and $60 \mu \mathrm{g} / \mathrm{ml}$, which were further diluted using mobile phase.

The sample solution was carried for testing APP, 20 capsules were taken and weighed individually. An appropriate portion of this powder, equivalent to $25 \mathrm{mg}$ was weighed and transferred in a $25 \mathrm{ml}$ volumetric flask, dissolving it in the mobile phase. The solution was sonicated for

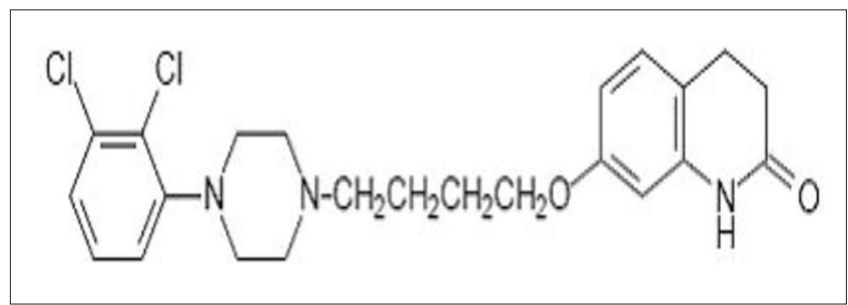

Fig. 1: Molecular structure of aripiprazole 
10 minutes to dissolve and remove the entire active form from the capsule. The solution was filtered if necessary.

\section{RESULTS AND DISCUSSION}

\section{Method validation}

The proposed method was validated as per ICH guidelines [21] which include specificity, linearity, precision, accuracy, limit of detection (LOD) and limit of quantification (LOQ), robustness and drug was also stressed to various degradation studies [22].

Linearity test solutions for the assay method were prepared from working APP stock solution at six concentration levels from $50 \%$ to $150 \%$ of assay analyte concentration $(10,20,30,40,50$ and $60 \mu \mathrm{g} / \mathrm{ml})$. The peak area versus concentration data were treated by least-squares linear regression analysis as shown in Table 1.

The precision of the related substances method verified by repeatability and by intermediate precision. Repeatability was checked by injecting six individual preparations of APP sample and \% relative standard deviation (RSD) of area for each concentration was calculated. The intermediate precision of the method was also evaluated using different analyst and performing the analysis on different days. Precision of assay method was evaluated by carrying out six independent assays of real sample of APP at $\mu \mathrm{g} / \mathrm{ml}$ level against qualified reference standard and $\%$ RSD was found not more than $2.0 \%$ and were therefore deemed as sufficient proof of the precision of this method. The \% RSD for repeatability and intermediate precision was shown in Table 1.

LOD and LOQ for sample were determined at a signal-to-noise ratio of 3:1 and 10:1, respectively, by injecting a series of dilute solutions with known concentrations. Precision study was also carried out at LOQ level by injecting six individual preparations of APP, and the \% RSD of the area was calculated. The values of LOD and LOQ were reported in Table 1.

The accuracy of the assay method was evaluated in triplicate using three concentration levels 50,100 and $150 \mu \mathrm{g} / \mathrm{ml}$ on real sample (100 mg capsules). Standard addition and recovery experiments were conducted on real sample to determine the accuracy of the related substance method. The study was carried out in triplicate using three concentration levels. The percentage of recoveries for APP was calculated and from the result obtained it can be concluded that the method delivers accurate results. The results of recovery studies were depicted in Table 1.

Robustness was determined for the developed method; experimental conditions were deliberately altered. The flow rate of the mobile phase was $1.0 \mathrm{ml} /$ minutes, to study the effect of flow rate was changed by 0.1 units. The effect of the column temperature was studied at $30^{\circ} \mathrm{C}$ and $40^{\circ} \mathrm{C}$ instead of $35^{\circ} \mathrm{C}$. Slight change in these parameters is not much effected and which shows the method is robust.

Solution stability of APP in the assay method was carried out by leaving both the test solutions of sample and reference standard in tightly capped volumetric flasks at room temperature for $48 \mathrm{hrs}$. The same sample solutions were assayed for $12 \mathrm{hrs}$ interval up to the study period.

Specificity is the ability of the method to measure the analyte response. It was tested by analyzing the prepared sample solutions

Table 1: Validation parameters determined during method validation for the detection and quantification of APP

\begin{tabular}{ll}
\hline Validation parameter & APP \\
\hline Linearity range & $10-60 \mu \mathrm{g} / \mathrm{ml}$ \\
Regression equation & $\mathrm{Y}=38093 \mathrm{X}-8150$ \\
Correlation coefficient $\left(\mathrm{r}^{2}\right)$ & 0.999 \\
$\mathrm{LOD}(\mu \mathrm{g} / \mathrm{ml})$ & 1.45 \\
$\mathrm{LOQ}(\mu \mathrm{g} / \mathrm{ml})$ & 4.40 \\
Precision $(\% \mathrm{RSD})$ & 1.08 \\
Intermediate precision $(\% \mathrm{RSD})$ & 1.46 \\
Assay $\%$ ) $( \pm \%$ RSD) & $100.06 \pm 1.42$ \\
Recovery $(\%)( \pm \%$ RSD) & $99.95 \pm 1.40$ \\
\hline
\end{tabular}

*The validation parameters were determined from the analysis of six standard solutions $(\mathrm{n}=6)$ over a concentration range of 10.0-60.0 $\mu \mathrm{g} / \mathrm{ml}$. $\%$ RSD: Percentage relative standard deviation, LOD: Limit of detection, LOQ: Limit of quantification, APP: Aripiprazole

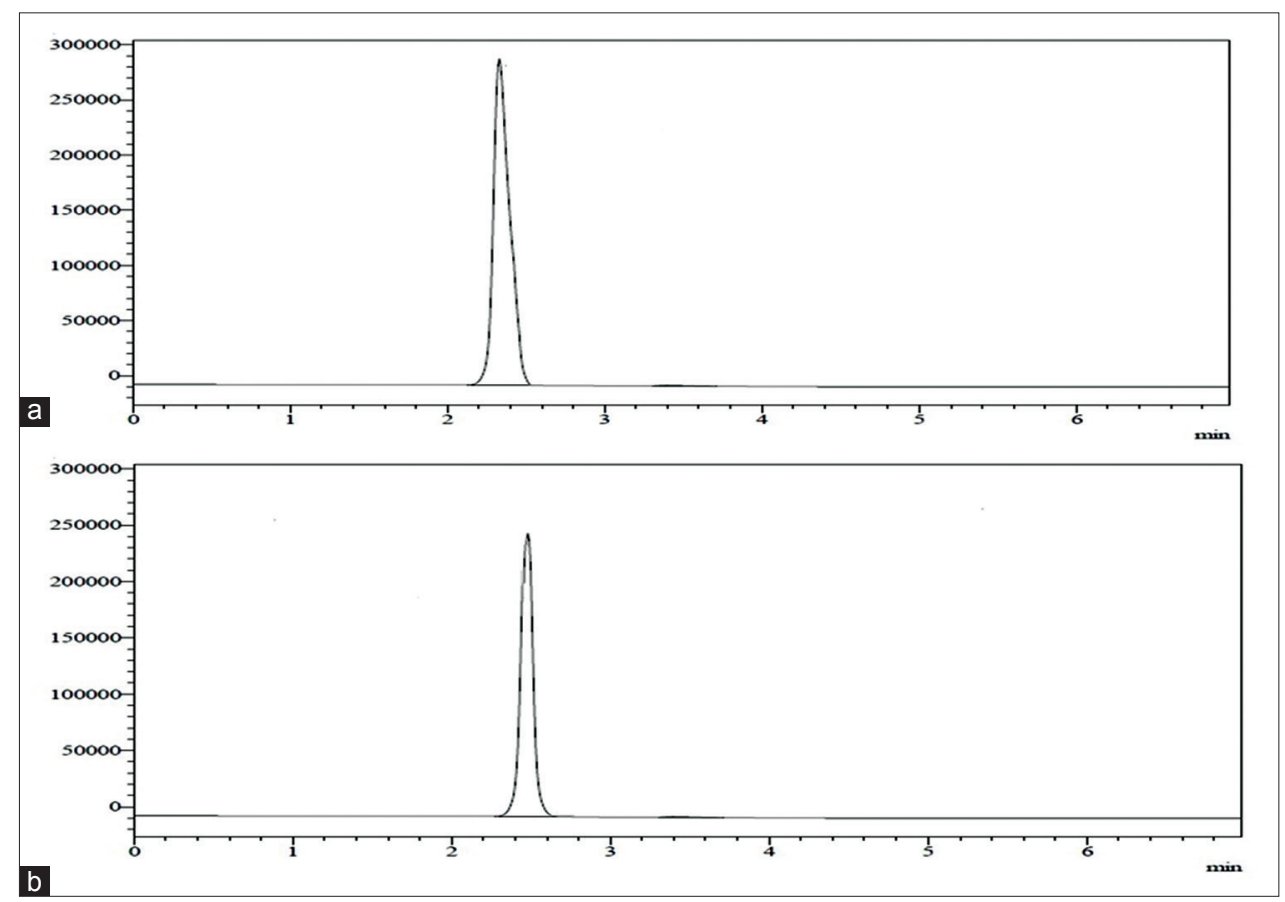

Fig. 2: Chromatograms obtained for aripiprazole (APP) during specificity testing with chromatogram (a) showing the peak obtained for APP from a standard solution and (b) showing the peak obtained for APP detected from a formulation 
which contained typical formulation with excipients. Chromatograms obtained for APP standard and sample solutions were shown in Fig. 2. Stress studies were performed for APP Capsules to provide an indication of the stability-indicating property and specificity of the proposed method. Intentional degradation was attempted with a stress condition of UV light $(254 \mathrm{~nm})$, heat $\left(70^{\circ} \mathrm{C}\right)$, acid $(0.1 \mathrm{M} \mathrm{HCl})$, base $(0.1 \mathrm{M} \mathrm{NaOH})$, and oxidation $\left(3.0 \% \mathrm{H}_{2} \mathrm{O}_{2}\right)$ to evaluate the ability of the proposed method to separate APP from its degradation product. For heat and light studies, the study period was 10 days. Whereas for hydrolytic, acid, base and oxidation, it was 24 hrs. Peak purity test was carried out for the APP peak by using PDA detector in stress samples.

APP was found to degrade significantly in oxidation $\left(3.0 \% \mathrm{v} / \mathrm{v}_{2} \mathrm{O}_{2}\right)$, and mild degradation was observed in thermal stress conditions shown in Fig. 3. APP was found to be stable under acid and base degradation, hydrolytic and photolytic conditions shown in Fig. 4. Photodiode array detector was employed to check and ensure the homogeneity and purity of APP peak in all the stressed sample solutions. Assay studies were carried out for stress samples against APP qualified working standard. The mass balance ( $\%$ assay $+\%$ degradants) results are presented in Table 2 . The purity and assay of APP was unaffected by degradation products and thus confirms the stability-indicating power of the developed method.

\section{CONCLUSION}

The simple isocratic reverse phase LC method developed for quantitative analysis of APP in bulk samples and pharmaceutical dosage forms is precise, accurate, linear, robust, and specific. Satisfactory results were obtained from validation of the method. The method is

Table 2: Summary of forced degradation studies

\begin{tabular}{llll}
\hline Stress condition & APP & & \\
\cline { 2 - 4 } & \% Purity & \% Degradation & $\begin{array}{l}\text { Mass } \\
\text { balance }\end{array}$ \\
\hline Acid degradation & 98.6 & 1.4 & 99.2 \\
Base degradation & 97.4 & 2.6 & 98.9 \\
Peroxide degradation & 88.2 & 11.8 & 99.1 \\
Thermal degradation & 89.7 & 10.3 & 98.7 \\
Photolytic degradation & 98.1 & 1.9 & 99.3 \\
\hline
\end{tabular}

APP: Aripiprazole

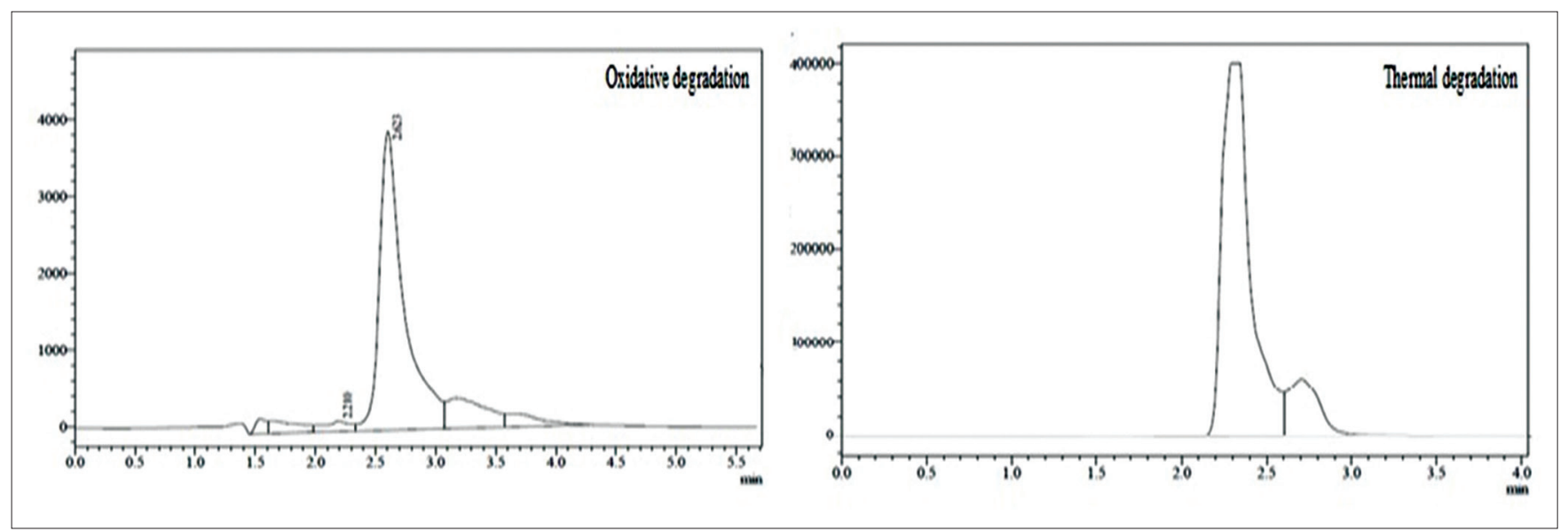

Fig. 3: Typical chromatograms of aripiprazole forced degradation samples (oxidative $\left[3.0 \% \mathrm{H}_{2} \mathrm{O}_{2}\right]$ and thermal studies)

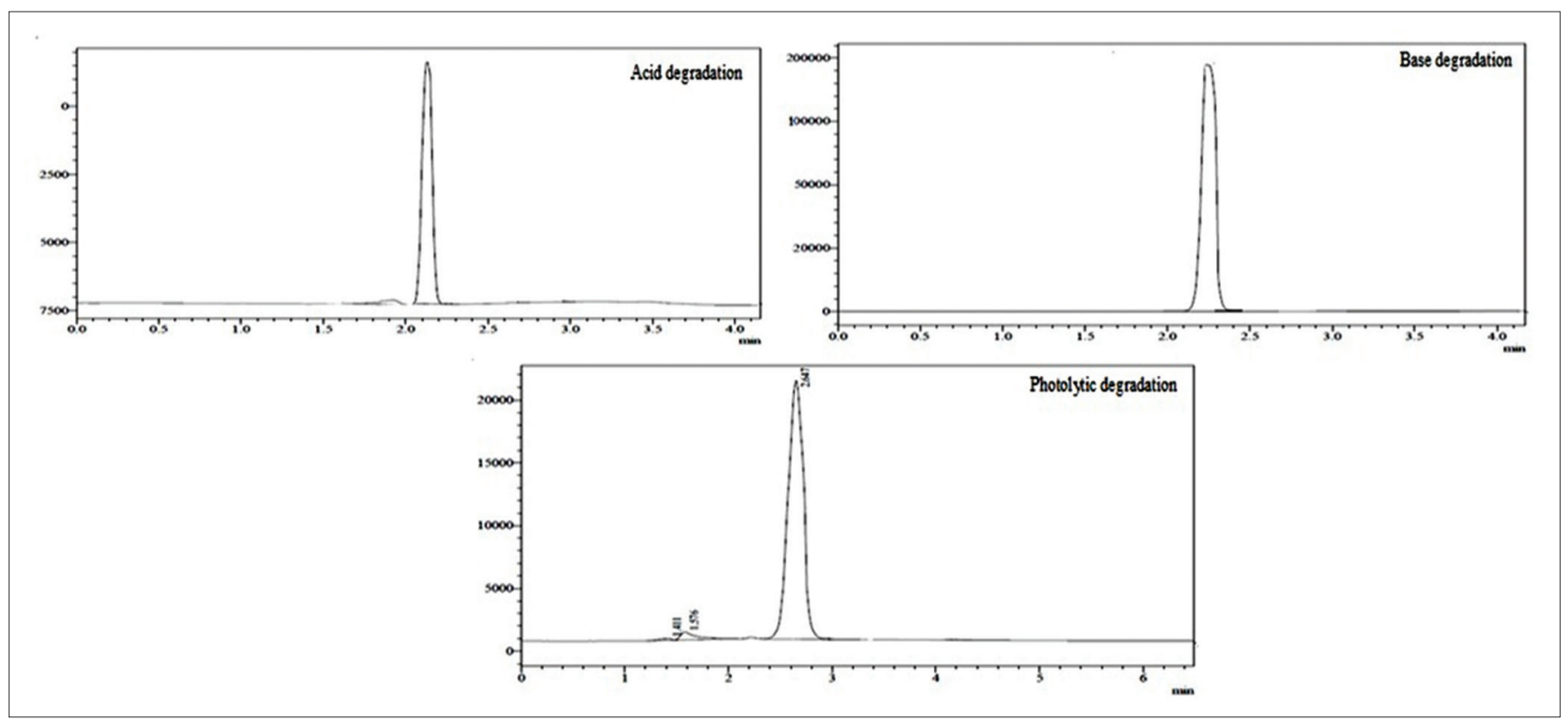

Fig. 4: Typical chromatograms of aripiprazole forced degradation samples (acid, base and photolytic studies) 
stability-indicating and can be used for routine analysis of production samples and to check the stability of samples of APP in bulk drugs and in pharmaceutical dosage forms.

\section{ACKNOWLEDGMENT}

The authors wish to thank Sun Pharma Laboratories for providing the gift sample. We also thank the Director, JNTUA-OTPRI for supporting this work by providing necessary facilities for developing of this method.

\section{REFERENCES}

1. Susan B. Merck Index, Encyclopedia of Chemicals and Pharmaceuticals $13^{\text {th }}$ ed. Whitehouse Station, NJ, USA: Merck \& Co Inc.; 2005. p. 1095.

2. Burris KD, Molski TF, Xu C, Ryan E, Tottori K, Kikuchi T, et al. Aripiprazole, a novel antipsychotic, is a high-affinity partial agonist at human dopamine D2 receptors. J Pharmacol Exp Ther 2002;302(1):381-9.

3. Kalaichelvi R, Thangabalan B, Rao DS, Jayachandran E. UV spectrophotometric determination of aripiprazole in bulk and pharmaceutical formulation. Eur J Chem 2009;6:S87-90.

4. Jain R, Kashaw SK, Jain R, Mishra P, Kohli DV. Visible spectrophotometric method for the determination of aripiprazole in tablets. Indian J Pharm Sci 2011;73(1):74-6.

5. Dey S, Chauhan N, Malairajan P, Murugan R, Das RC, Ahmad S. A simple and rapid spectrophotometric determination of aripiprazole in pharmaceutical dosage form. Int J Drug Dev Res 2011;3:205-8.

6. Sachdev Y. Spectrophotometric determination of aripiprazole in tablet formulation. Indian Pharm 2009;8:69-71.

7. Eldidamony AM, Hafeez SM, Abdel-Hafez MM. Spectrophotometric determination of aripiprazole, clozapine and sulpiride by ion - Pair extraction in tablets and biological fluids. Int J Pharm Pharm Sci 2015;7(1):178-84

8. Liang F, Terry AV, Bartlett MG. Determination of aripiprazole in rat plasma and brain using ultra-performance liquid chromatography/ electrospray ionization tandem mass spectrometry. Biomed Chromatogr 2012;26(11):1325-32.

9. Thakkar RS, Saravaia HT, Ambasana MA, Kaila HO, Shah AK. A Chromatographic determination of aripiprazole using HPLC and UPLC: A comparative validation study. Indian J Pharm Sci 2011;73(4):439-43

10. Sastry BS, Gananadhamu S, Rao GD. RP-HPLC determination of aripiprazole in pharmaceutical formulations. Asian $\mathrm{J}$ Chem 2009;21(9):6643-6.

11. Shimokawa Y, Akiyama H, Kashiyama E, Koga T, Miyamoto G.
Highperformance liquid chromatographic methods for the determination of aripiprazole with ultraviolet detection in rat plasma and brain: Application to the pharmacokinetic study. J Chromatogr B Analyt Technol Biomed Life Sci 2005;821(1):8-14.

12. Mondal P, Rani SS, Alekhya K. A new stability indicating validated method for the determination of aripiprazole in bulk and tablet dosage form using RP-HPLC. Int J Pharm Pharm Sci 2013;5(4):660-5.

13. Huang $\mathrm{HC}$, Liu CH, Lan $\mathrm{TH}, \mathrm{Hu} \mathrm{TM}$, Chiu HJ, Wu YC, et al. Detection and quantification of aripiprazole and its metabolite, dehydroaripiprazole, by gas chromatography-mass spectrometry in blood samples of psychiatric patients. J Chromatogr B Analyt Technol Biomed Life Sci 2007;856(1-2):57-61

14. Ravinder S, Bapuji AT, Mukkanti K, Raju DR, Ravikiran HL, Reddy DC. Development and validation of an LC-ESI-MS method for quantitative determination of aripiprazole in human plasma and an application to pharmacokinetic study. J Chromatogr Sci 2012;50(10):893-901.

15. Song $\mathrm{M}, \mathrm{Xu} \mathrm{X}$, Hang $\mathrm{T}$, Wen $\mathrm{A}$, Yang L. Development of an LC-MS/MS method for the simultaneous quantification of aripiprazole and dehydroaripiprazole in human plasma. Anal Biochem 2009;385(2):270-7.

16. Kubo M, Mizooku Y, Hirao Y, Osumi T. Development and validation of an LC-MS/MS method for the quantitative determination of aripiprazole and its main metabolite, OPC-14857, in human plasma. J Chromatogr B Analyt Technol Biomed Life Sci 2005;822(1-2):294-9.

17. Patel DP, Sharma P, Sanyal M, Shrivastav PS. SPE-UPLC-MS/MS method for sensitive and rapid determination of aripiprazole in human plasma to support a bioequivalence study. J Chromatogr B Analyt Technol Biomed Life Sci 2013;925:20-5

18. Zuo XC, Wang F, Xu P, Zhu RH, Li HD. LC-ESI-MS for rapid and sensitive determination of aripiprazole in human plasma. Chromatographia 2006;64:387-91

19. Hwang PL, Wei SY, Yeh HH, Ko JY, Chang CC, Chen SH. Simultaneous determination of aripiprazole and its active metabolite, dehydroaripiprazole, in plasma by capillary electrophoresis combining on-column field-amplified sample injection and application in schizophrenia. Electrophoresis 2010;31(16):2778-86.

20. Musenga A, Saracino MA, Spinelli D, Rizzato E, Boncompagni G, Kenndler E, et al. Analysis of the recent antipsychotic aripiprazole in human plasma by capillary electrophoresis and high-performance liquid chromatography with diode array detection. Anal Chim Acta 2008;612(2):204-11.

21. Available from: http://www.ich.org/fileadmin/Public_Web_Site/ICH Products/Guidelines/Quality/Q2 R1/Step4/Q2 R1 Guideline.pdf. [Last accessed on 2016 Aug 25].

22. ICH. Stability Testing of New Drug Substances and Products (Q1AR2): International Conference on Harmonization. Geneva: IFPMA; 2000. 